\title{
Population Dynamics of Crenarchaeota and Euryarchaeota in the Mixing Front of River and Marine Waters
}

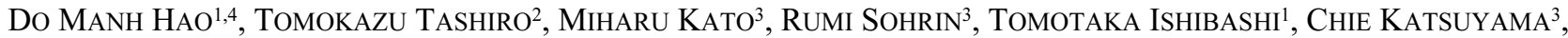

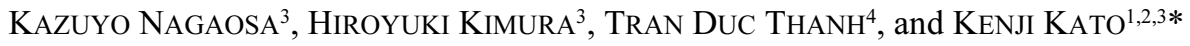 \\ ${ }^{1}$ Department of Environment and Energy System, Graduate School of Science and Technology, Shizuoka University, 836 Ohya, \\ Suruga-ku, Shizuoka 422-8529, Japan; ${ }^{2}$ Department of Geosciences, Graduate School of Science, Shizuoka University, 836 \\ Ohya, Suruga-ku, Shizuoka 422-8529, Japan; ${ }^{3}$ Department of Geosciences, Faculty of Science, Shizuoka University, 836 \\ Ohya, Suruga-ku, Shizuoka 422-8529, Japan; and ${ }^{4}$ Institute of Marine Environments and Resources, Vietnam Academy \\ of Science and Technology, 246 Da Nang Street, Ngo Quyen, Hai Phong, Vietnam
}

(Received January 29, 2010-Accepted March 18, 2010—Published online April 23, 2010)

A transect from the Tomoe River Mouth through Shimizu Port to Suruga Bay, Japan, was examined between 2005 and 2009 to reveal the population dynamics of Crenarchaeota and Euryarchaeota in an estuary environment. Crenarchaeota tended to increase in abundance in waters deeper than $100 \mathrm{~m}$ compared with Euryarchaeota, and comprised $11 \%$ of total direct counts. Archaeal abundance was highest in the Tomoe River Mouth, with a strong negative correlation between surface euryarchaeal abundance and salinity $(P<0.001)$. The diversity index for the phylotypic archaeal community in the mouth was three times higher than that at sites St $1-1 \mathrm{~m}$ and St $1-10 \mathrm{~m}$ in the estuary, and OTUs represented most of the OTU groups at the sites. Three of the seven total OTUs, which comprised $83.6 \%$ of the 140 sequenced clones in the estuary, were related to the OTUs in the mouth with similarities higher than $97 \%$. A significant proportion of the archaeal community appears to be derived from the Tomoe River. The two dominant phylotypes of the archaeal community in Shimizu Port, belonging to MGI and MGII, occurred ubiquitously.

Key words: Crenarchaeota, Euryarchaeota, Tomoe River Mouth, Shimizu Port, Suruga Bay

The idea that Archaea only occur in extreme environments, such as hot springs, hydrothermal vents, salt lakes, and subterranean environments, has been challenged by their discovery in the Pacific Ocean at a depth of $500 \mathrm{~m}$ (10) and in coastal waters of North America (7). Archaea have now been discovered throughout the world's oceans, from coastal to offshore zones and from the surface to aphotic depths $(6,21,23,31)$. They have been found widely in other non-extreme environments, including forest, terrestrial, and freshwater habitats $(2,4,14,16,20,35)$.

Four major groups of planktonic marine Archaea have been discovered throughout the world's oceans, of which Marine Group I Crenarchaeota (MGI) and Marine Group II Euryarchaeota (MGII) are predominant in abundance. Two other planktonic archaeal groups, Marine Group III (MGIII) and Marine Group IV (MGIV), appear to be low in abundance and have only been found in waters below the photic zone and in the deep ocean (8). In temperate regions, MGII tends to predominate at the surface, whereas MGI predominates in deep waters and can represent more than $20 \%$ of all microbial cells at depths below $100 \mathrm{~m}(8,17)$.

Seasonal variability in archaeal abundance has been observed at some locations, and Archaea are abundant in late winter and early spring in the nearshore waters of Anvers Island (23). Crenarchaeota also tend to be highly abundant in water at the surface in winter west of the Antarctic Peninsula (5) and in the southern part of the North Sea (12). Euryarchaeota predominate in summer in the North Sea and

\footnotetext{
* Corresponding author. E-mail: skkato@ipc.shizuoka.ac.jp; Tel: +81-54-238-4950; Fax: +81-54-238-4950.
}

in the northwestern Black Sea $(12,30)$.

The phylogenetic diversity of marine planktonic archaeal communities is low, and most libraries are dominated by only one or two operational taxonomic units (OTUs) (22). Some marine crenarchaeal phylotypes are classified into the same clusters as Crenarchaeota from extreme environments and non-extreme environments, such as forests, paddy soils, freshwater, and anaerobic digesters $(8,14,22)$. A recent study of the particle-rich waters of the Beaufort Shelf and Franklin Bay found that many Archaea in these waters are derived from the Mackenzie River, because the river is the regional particle source with the highest archaeal abundance and there was a strong positive correlation $(P<0.001)$ between the archaeal and particle concentrations (38). In addition to findings on the distribution of Archaea, a proteinlevel analysis confirmed that the DNA polymerase amino acid sequence of Cenarchaeum symbiosum, a symbiotic archaeon, closely resembles those of the thermostable DNA polymerases from the extreme thermophiles Sulfolobus acidocaldarius and Pyrodictium occultum (54\% and 53\%, respectively) (26). However, the analysis of ribosomal proteins indicated that $C$. symbiosum were not more closely related to hyperthermophilic crenarchaeota than they were to Euryarchaeota. The mesophilic crenarchaeota could have diverged before the speciation of Euryarchaeota and hyperthermophilic crenarchaeota (3). Thus, the evolutional origin of MGI remains a puzzle.

Planktonic Archaea have been monitored in Suruga Bay, Japan, since 2001 at two stations: St.1, located within Shimizu Port, $1.5 \mathrm{~km}$ northeast of the mouth of the Tomoe River, which is expected to be strongly affected by fresh- 
water supply and urban activities; and St.2, located outside Shimizu Port, which represents the coastal environment of Suruga Bay, which is less strongly influenced by domestic activities. The Archaea constituted $0.1 \%-3.2 \%$ of total direct counts (TDC), and in situ observations indicated a negative correlation between archaeal abundance and salinity $(P<0.05)(31)$. The present study examined the temporal and spatial distributions of the planktonic archaeal community along a curved transect from the Tomoe River Mouth through Shimizu Port to Suruga Bay, and given environmental parameters, to determine the interaction of the Archaea between river and marine waters, and to understand the relationship between the Archaea and certain environmental variables.

\section{Materials and Methods}

\section{Study sites and sample collection}

Water samples were measured directly in the field and collected with a Niskin sampler (5026-D, Rigosha, Tokyo, Japan). They were then immediately divided among sterilized Pyrex bottles for environmental and microbial analyses at the stations in the Tomoe River mouth, inside Shimizu Port (St.1), or outside the port in Suruga Bay (St.2-St.5) at different depths, between 2005 and 2009 (Fig. 1).

\section{Measurement of environmental parameters}

Water temperature, $\mathrm{pH}$, electrical conductivity (EC), and dissolved oxygen (DO) levels were measured at the sites using a water quality checker (U-10, Horiba, Tokyo, Japan); salinity was measured with an EC meter (CM-14P, TOA-DKK, Tokyo, Japan); and chlorophyll $a$ was measured with a fluorescence spectrophotometer (RF-5300, Shimadzu, Kyoto, Japan). The concentrations of nutrients $\left(\mathrm{NO}_{3}{ }^{-}, \mathrm{NO}_{2}{ }^{-}, \mathrm{NH}_{4}{ }^{+}\right.$, and $\left.\mathrm{PO}_{4}{ }^{3-}\right)$ were measured with a nutrient analyzer (TrAAcs 2000, Bran+Luebbe, Nordersted, Germany).

\section{Prokaryote abundance analysis}

Total prokaryotes (TDC). The samples were fixed with neutralized formaldehyde $(2 \%$ final concentration, $\mathrm{v} / \mathrm{v})$, then stained with 4',6-diamidino-2-phenylindole (DAPI; final concentration, $\left.0.01 \mu \mathrm{g} \mathrm{mL} \mathrm{m}^{-1}\right)(24)$ and quantified directly under an epifluorescence microscope (BX51-FLA, Olympus, Tokyo, Japan).

Quantitative oligonucleotide hybridization. The water samples were fixed with paraformaldehyde (final concentration 3\%), kept at $4^{\circ} \mathrm{C}$ for up to $24 \mathrm{~h}$, and filtered onto nucleopore filters with a 0.2 $\mu \mathrm{m}$ pore size (Whatman, Cambridge, UK) using glass microfiber supporting filters. The prokaryote-containing filters were rinsed three times with filtered phosphate-buffered saline and dehydrated in three consecutive ethanol concentrations, $50 \%, 80 \%$, and $99.5 \%$. After the filters had been dried at room temperature, they were stored at $-20^{\circ}$ C. Bacteria, Crenarchaeota, and Euryarchaeota were counted according to the improved Catalyzed Reporter DepositionFluorescence In Situ Hybridization (CARD-FISH) protocol described by Teira et al. (32). The horseradish-peroxidase-labeled probes specific for Bacteria, Crenarchaeota, and Euryarchaeota were EUB338 (5'-GCTGCCTCCCGTAGGAGT-3') (1), CREN537 (5'-TGACCACTTGAGGTGCTG-3') (32), and EURY806 (5'-CACAGCGTTTACACCTAG-3') (32), respectively. The hybridization buffer consisted of $0.9 \mathrm{M} \mathrm{NaCl}, 20 \mathrm{mM}$ Tris- $\mathrm{HCl}(\mathrm{pH} 7.5), 10 \%$ dextran sulfate, $0.02 \%$ sodium dodecyl sulfate, $1 \%$ blocking reagent, and $55 \%$ formamide (for EUB338) or $20 \%$ formaldehyde (for CREN537 and EURY806). Hybridization was performed at $35^{\circ} \mathrm{C}$ for $2 \mathrm{~h}$ (Bacteria) or $10 \mathrm{~h}$ (Archaea). The numbers of Bacteria, Crenarchaeota, and Euryarchaeota were counted based on pictures taken under a universal epifluorescence microscopic system (BX51-FLA, Olympus) equipped with a digital camera (DP71, Olympus).

\section{Analysis of archaeal phylotypic community composition}

DNA extraction. The bulk DNAs of the microbes trapped on the filter units were extracted using the method described by Somerville et al. (28). The filters were washed with $10 \mathrm{~mL}$ of SET buffer (20\% sucrose, $50 \mathrm{mM}$ EDTA, and $50 \mathrm{mM}$ Tris- $\mathrm{HCl}$ [pH 8.0]), and $1.8 \mathrm{~mL}$ of SET buffer was added to each filter unit. The microbial cells were lysed in the filter units with solutions of lysozyme and proteinase $\mathrm{K}$. The bulk DNAs were extracted with a phenol-chloroform-isoamyl alcohol mixture $(25: 24: 1, \mathrm{v} / \mathrm{v} / \mathrm{v} ; \mathrm{pH}$ 8.0) and concentrated by ethanol precipitation. A commercial Soil DNA kit (MO-BIO, Carlsbad, CA, USA) was used to repurify the DNA samples that could not be amplified by PCR. With this kit, $50 \mu \mathrm{L}$ of inhibitor removal solution (IRS) was added to $100 \mu \mathrm{L}$ of the primary DNA solution, which was then incubated at room temperature for $10 \mathrm{~min}$; after $60 \mu \mathrm{L}$ of $\mathrm{S} 2$ solution was added, the

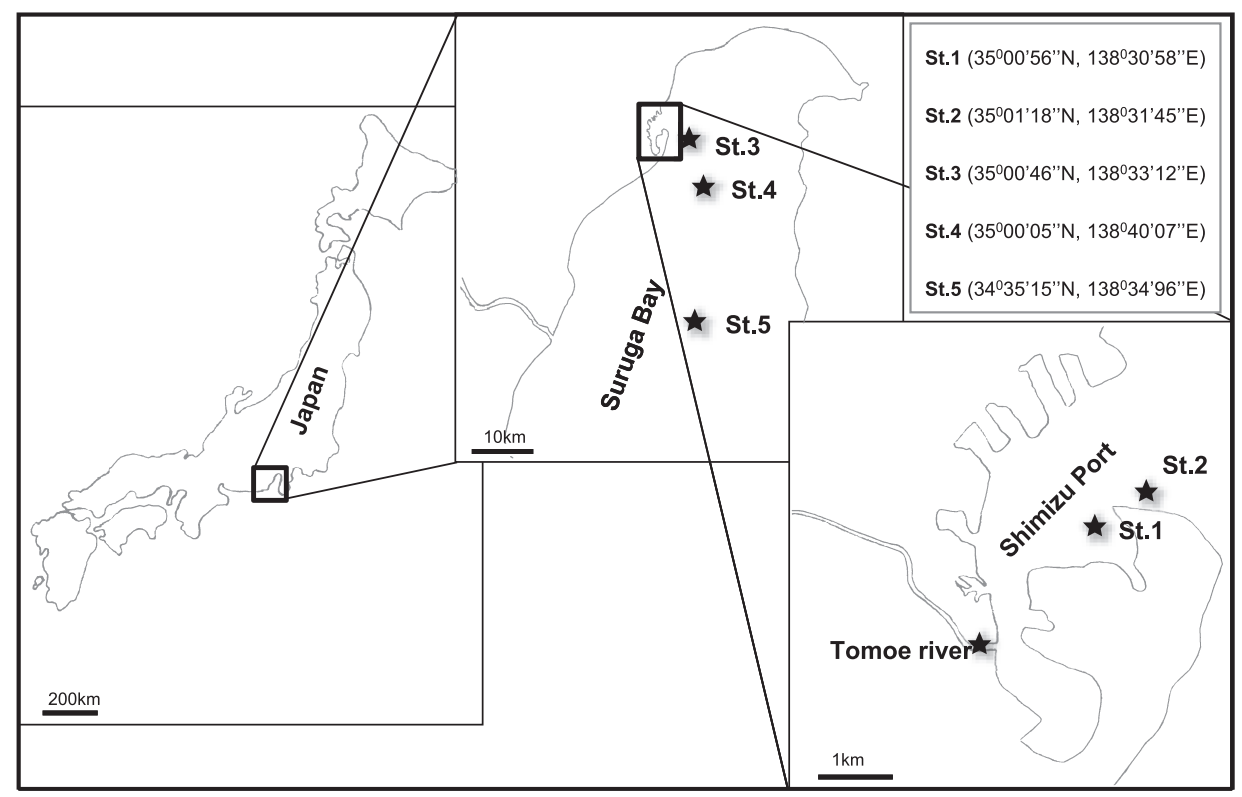

Fig. 1. Sampling stations in the Tomoe River Mouth, Shimizu Port, and Suruga Bay at different depths. 
samples were vortexed for $5 \mathrm{~s}$ and incubated at $4^{\circ} \mathrm{C}$ for $5 \mathrm{~min}$. The tubes were centrifuged for $1 \mathrm{~min}$ at $10,000 \times \mathrm{g}$ and the supernatants were transferred into new $2 \mathrm{~mL}$ tubes. After the addition of $230 \mu \mathrm{L}$ of S3 solution, the samples were vortexed for $5 \mathrm{~s}$ and loaded onto spin filters, which were centrifuged at $10,000 \times \mathrm{g}$ for $1 \mathrm{~min}$. The subsequent steps were performed strictly according to the MO-BIO protocol for the Soil DNA Isolation Kit.

Cloning and sequencing of archaeal 16S rRNA gene fragments. The archaeal $16 \mathrm{~S}$ rRNA genes in the bulk DNAs extracted from surface water samples were amplified by PCR using KOD-Plus DNA polymerase (Toyobo, Osaka, Japan) and the Archaea-specific primer set Arch21F (5'-TTCCGGTTGATCCYGCCGGA-3') (7) and Arch915R (5'-GTGCTCCCCCGCCAATTCCT-3') (29). The PCR amplicons were cloned using the Zero Blunt TOPO PCR Cloning Kit (K2880-20, Invitrogen, Carlsbad, CA, USA). Clone libraries of the archaeal 16S rRNA gene fragments were constructed separately. The sequences of the inserted PCR amplicons from selected recombinant colonies were commercially analyzed by Takara Bio (Otsu, Japan) using the vectorspecific pair of primers $\mathrm{T} 7$ and $\mathrm{T} 3$ for the sequencing reactions.

Archaeal phylogenetic analysis. First, sequences of $c a .650$ bases were checked for homology with the primer $21 \mathrm{~F}$ using GENETYX ver. 8 (GENETYX, Tokyo, Japan). Second, only primer-21F-compatible sequences were used to check for chimeric artifacts using the Check-Chimera program (http://foo.maths.vq. edu.au/ huber/bellerophon.p1). Third, nonartifact sequences were rapidly classified into high-order taxonomic units (37) with the Naïve Bayesian Classifier (http://rdp.cme.msu.edu/index.jsp); the sequences identified as "unclassified roots" were not used for the subsequent analysis. Fourth, well-known culturable and unculturable closest relatives were identified with the Basic Local Alignment Search Tool (BLAST) in the DNA Data Bank of Japan (DDBJ, http://www.ddbj.nig.ac.jp/). Our 186 sequences and their closest relatives retrieved from the database, together with representative sequences from the different archaeal Marine Groups, were aligned using the CLUSTAL W package (34). The clones with homology values of $>80 \%$ and $>98 \%$ were classified into phylogenetic groups and operational taxonomic units (or clusters), respectively [improved from Schloss and Handelsman (27)]. Finally, a phylogenetic tree was produced using the neighbor-joining algorithm of the NJ plot program (25).

\section{Statistical analysis}

The relationships between prokaryotic numbers (TDC, Bacteria, Crenarchaeota, and Euryarchaeota) and environmental variables were identified with the Pearson product-moment correlation coefficient using Microsoft Excel software. The diversity of the archaeal phylotypic communities was calculated with the ShannonWiener index.

\section{Nucleotide sequence accession numbers}

The nucleotide sequences, representative of partial archaeal $16 \mathrm{~S}$ rRNA genes, identified in this study have been deposited in the DDBJ/EMBL/GenBank nucleotide sequence databases with the accession numbers: AB538507-538537 for TR0-J01, TR0-AA1, TR0-B01, TR0-AE1, TR0-AD1, TR0-L01, TR0-O01, TR0-E01, TR0-AF1，TR0-R01，TR0-G01，TR0-I01，TR0-F01，TR0-AB1, TR0-K01, TR0-P01, TR0-M01, TR0-N01, TR0-A07, TR0-D01, TR0-H02, TR0-AC1, TR0-C01, S101-A19, S101-B01, S101-C01, S110-01, S110-02, S110-04, S110-05, and S110-06.

\section{Results}

Environmental parameters (Fig. S1)

Environmental parameters in a transect from Tomoe River Mouth through Shimizu Port to Suruga Bay were monitored temporally and spatially. The surface water temperature changed seasonally in the range of $14.2^{\circ} \mathrm{C}$ to $28.8^{\circ} \mathrm{C}$ during the observation period (Fig. S1a). Salinity outside Shimizu Port was stable both temporally and spatially in the range of $33 \%$ - $34 \%$, while salinity at the Tomoe River Mouth and St $1-1 \mathrm{~m}$ fluctuated widely from $0 \%$ to $18 \%$ and from $22 \%$ o to $34 \%$, respectively (Fig. S1b). There were three clearly evident trends in chlorophyll $a$. The concentrations decreased from Shimizu Port seaward, were higher at the surface than at deeper sites, and were higher in summer than in other seasons. The chlorophyll $a$ concentration mainly varied in the range $0.228-11.38 \mathrm{mg} \mathrm{m}^{-3}$ at the surface and decreased to less than $0.035 \mathrm{mg} \mathrm{m}^{-3}$ at below $300 \mathrm{~m}$ (Fig. $\mathrm{S} 1 \mathrm{~h}) . \mathrm{NO}_{3}{ }^{-}$concentrations ranged from 0.02 to $7.21 \mu \mathrm{M}$ at the surface, and tended to increase with depth to $41.68 \mu \mathrm{M}$ at $1,000 \mathrm{~m}$. There was no seasonal or horizontal variability in $\mathrm{NO}_{3}{ }^{-}$(Fig. S1d). $\mathrm{NH}_{4}{ }^{+}$concentrations decreased from inside (St.1) to outside Shimizu Port. The concentration of $\mathrm{NH}_{4}^{+}$ was often higher at the surface than at deeper sites (Fig. S1f). The trend of change in $\mathrm{PO}_{4}{ }^{3-}$ was similar to that in $\mathrm{NO}_{3}{ }^{-}$; the concentration ranged from 0.03 to $0.51 \mu \mathrm{M}$ at the surface and tended to increase with depth, reaching $3.05 \mu \mathrm{M}$ at $1,351 \mathrm{~m}$ (Fig. S1g).

\section{Prokaryote abundance}

Total prokaryotes (Fig. S2a). TDC varied mainly in the range of $4.69 \times 10^{5}-1.18 \times 10^{6}$ cells $\mathrm{mL}^{-1}$ in water at the surface. There were three clear trends: first, TDC decreased from the Tomoe River toward the bay; second, it decreased from the surface to the deeper waters; and third, TDC was higher in summer than in the other seasons. Exceptions to these trends were 1) TDC at the Tomoe River site on 7th August 2009, which was less than that at St1-1m, and 2) TDC at St. 3 at $10 \mathrm{~m}$ on 10th August 2007, which was higher than that at $1 \mathrm{~m}$.

Bacteria (Fig. S2b). In water at the surface, the numbers of Bacteria varied from $1.30 \times 10^{5}$ to $6.22 \times 10^{5}$ cells $\mathrm{mL}^{-1}$. We also observed trends in bacterial numbers similar to those for chlorophyll $a$ and TDC. There were three clearly changing trends in TDC; first, it decreased from the Tomoe River site toward the bay; second, it decreased from the surface to deeper waters; and third, the abundance was higher in summer than in other seasons.

Crenarchaeota (Fig. S2c). The abundance of Crenarchaeota mainly varied from $1.40 \times 10^{3}$ to $2.58 \times 10^{5}$ cells $\mathrm{mL}^{-1}$. Although the trends in Crenarchaeota abundance did not fully parallel those of chlorophyll $a$, TDC, and Bacteria abundance, Crenarchaeota numbers decreased from the surface to deeper waters and were higher in summer than in other seasons.

Euryarchaeota (Fig. S2d). The abundance of Euryarchaeota ranged mainly from $1.23 \times 10^{3}$ to $2.57 \times 10^{5}$ cells $\mathrm{mL}^{-1}$, decreased from the Tomoe River site to Suruga Bay, and decreased from the surface to deeper waters. There was no clear trend in Euryarchaeota numbers with the seasonal cycle. This archaeal group was not detected effectively with the CARD-FISH technique at deep sites, especially below $100 \mathrm{~m}$, because the abundance of the Euryarchaeota at these depths may have been below the limit of detection (around $10^{3}$ cells $\mathrm{mL}^{-1}$ for a sample filtration volume of $4 \mathrm{~mL}$ for each filter). 


\section{Composition of the archaeal phylotypic community (Fig. 2)}

Tomoe River. Twenty four OTUs were identified in the sample taken from the Tomoe River site on 19th May 2009. The dominant OTU (TR0-A07) was represented by 11 clones $(23.9 \%)$, whereas all other OTUs contained fewer than 4 clones. One OTU was identified as an unclassified root by the Naïve Bayesian Classifier, and the remaining 23 OTUs were categorized into eight different archaeal groups. Four groups of Crenarchaeota were classified into MGI, a Miscellaneous Crenarchaeotic Group (MCG), the same group containing Candidatus Nitrososphaera gargensis (EU281336, EU281335), and the remaining group was identified as a new freshwater Crenarchaeota group. There was one group of Euryarchaeota together with clones from an anaerobic digester of a gas plant and clones from methanogenic granular sludge, and one group belonging to Marine Group III. The two remaining groups were identified as new freshwater Archaea.

St1-1m. Only three archaeal OTUs were found at St1-1m on 19th May 2009 and the dominant OTU (S101-A19) comprised $95.6 \%$ of the 45 sequenced clones. Two other OTUs, S101-C01 and S101-B01, each comprised only $2.2 \%$ of all the clones from the site. S101-A19 was phylogenetically close to S101-C01, with a similarity of $97 \%$, and the two OTUs were classified into MGI. S101-B01 was classified into a new group of Archaea together with OTU TR0-AA1 from the Tomoe River site, with which it shared $100 \%$ homology.

St1-10m. Six archaeal OTUs were found at St1-10m

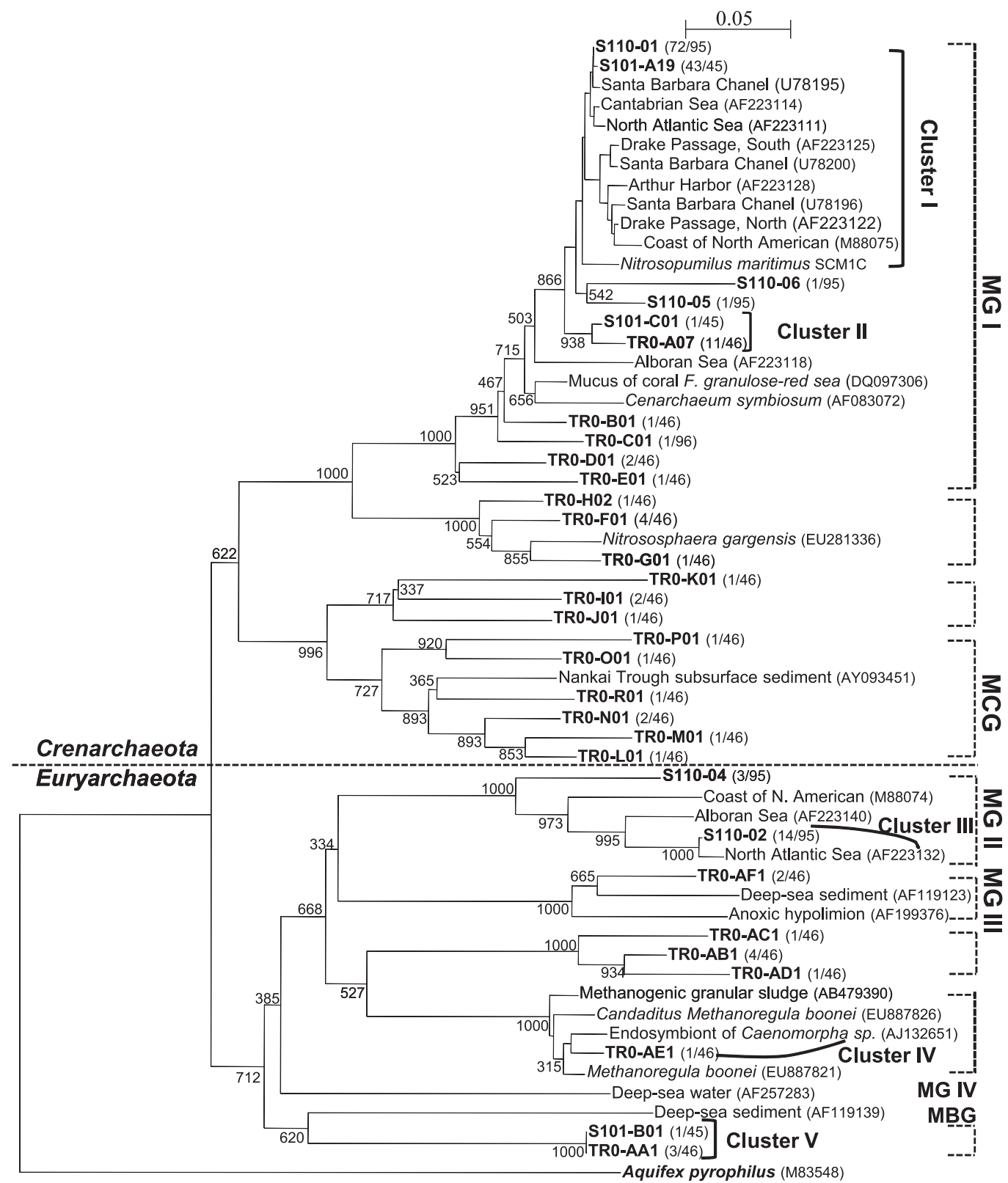

Fig. 2. Phylogenetic tree of planktonic archaeal 16S rRNA sequences in Tomoe River Mouth and Shimizu Port. Aquifex pyrophilus was used as an outgroup. TRO-XX, S101-XX and S110-XX indicate samples from Tomoe River, St1-1m and St1-10m, respectively. (xx/xx), contribution of clones per total clones. 
on 19th May 2009. The two dominant OTUs, S110-01 and S110-02, comprised $75.8 \%$ and $14.7 \%$, respectively, of the 95 sequenced archaeal clones. One OTU was identified as an unclassified root by the Naïve Bayesian Classifier; three OTUs, S110-01, S110-05, and S110-06, were classified as MGI Crenarchaeota, and the remaining two OTUs, S110-02 and S110-04, were classified as MGII Euryarchaeota.

\section{Discussion}

\section{Temporal dynamics}

The abundances of TDC and Bacteria were significantly higher in August than in the other months examined, and both TDC and Bacteria correlated positively with temperature $(P<0.05$; Fig. S3a, e). Similar findings have been reported for the relationship between prokaryotic abundance and temperature (31) in the same study area and in the Delaware estuary (18). However, we found no significant relationship between the abundances of the Crenarchaeota and Euryarchaeota and temperature, even when their abundances were investigated carefully with the CARD-FISH technique, which allowed us to detect archaeal cells with higher sensitivity than that possible using the standard FISH technique (32). In the present study, the proportions of Crenarchaeota and Euryarchaeota combined at St.1 and St. 2 ranged from $1.0 \%$ to $18.1 \%$ of TDC, with a mean value of $10.5 \%$, whereas they were reported to fluctuate from $0.1 \%$ to $3.0 \%$ of TDC when estimated with a standard FISH technique in a previous study (31). Temperature does not seem to regulate the abundance of the two archaeal subdomains in the area studied.

\section{Spatial variability and environmental gradients}

The water examined in this study can be separated into three zones: the Tomoe River, and inside and outside Shimizu Port. The port area represented by site St.1 is a semi-enclosed system containing the mixing front of the Tomoe River and the region outside the port. The water in
Shimizu Port is continuously affected by inflowing water from the Tomoe River and intrusion of the water mass from Suruga Bay, through tidal and hydrodynamic processes. The wide fluctuation in salinity, from $23 \%$ to $33 \%$, indicates that the zone is strongly influenced by the mass of freshwater discharged from the Tomoe River. Fukue et al. (11) showed that suspended solids bring various compounds from the river through the port, discharging them into Suruga Bay; consequently, the port acts as a buffer zone insofar as it mitigates diffusion of the compounds brought down by the river.

The levels of TDC and Bacteria inside the port (St.1) were lower than those at the Tomoe River site, but higher than those in Suruga Bay. Statistical analysis showed that TDC and Bacteria were significantly positively related to chlorophyll $a$ levels $(P<0.001$ for both; Fig. S3c, e). Salinity correlated negatively with TDC $(P<0.05$; Fig. S3b) but there was no significant correlation between salinity and Bacteria. This finding suggests that the abundance of Bacteria is linked mainly by primary production and is not directly affected by fresh water from the Tomoe River.

A decreasing trend in the abundance of surface planktonic Euryarchaeota is clearly apparent in Fig. 3a, as is the relative contribution of Euryarchaeota to TDC, which was $15.7 \%$ at the Tomoe River site, $8.7 \%$ at St.1, and $1.9 \%$ at the sites outside Shimizu Port. Statistical analysis showed a negative correlation between salinity and Euryarchaeota $(P<0.001$; Fig. S3f). Euryarchaeota were also particularly prominent $(11 \%-22 \%$ of total prokaryotic plankton) in the low-salinity waters of the coastal northwestern Black Sea (30). An example of the transportation of Euryarchaeota from the Tomoe River to Shimizu Port is demonstrated with the specific OTU (S101-B01) at St1-1m, which is identical to an OTU (TR0-AA1) found at the Tomoe River site, with a similarity of $100 \%$. These two OTUs have no significant relationship to any other OTUs found at St1-10m, and with any known culturable or unculturable OTU. These findings support the scenario that a significant proportion of

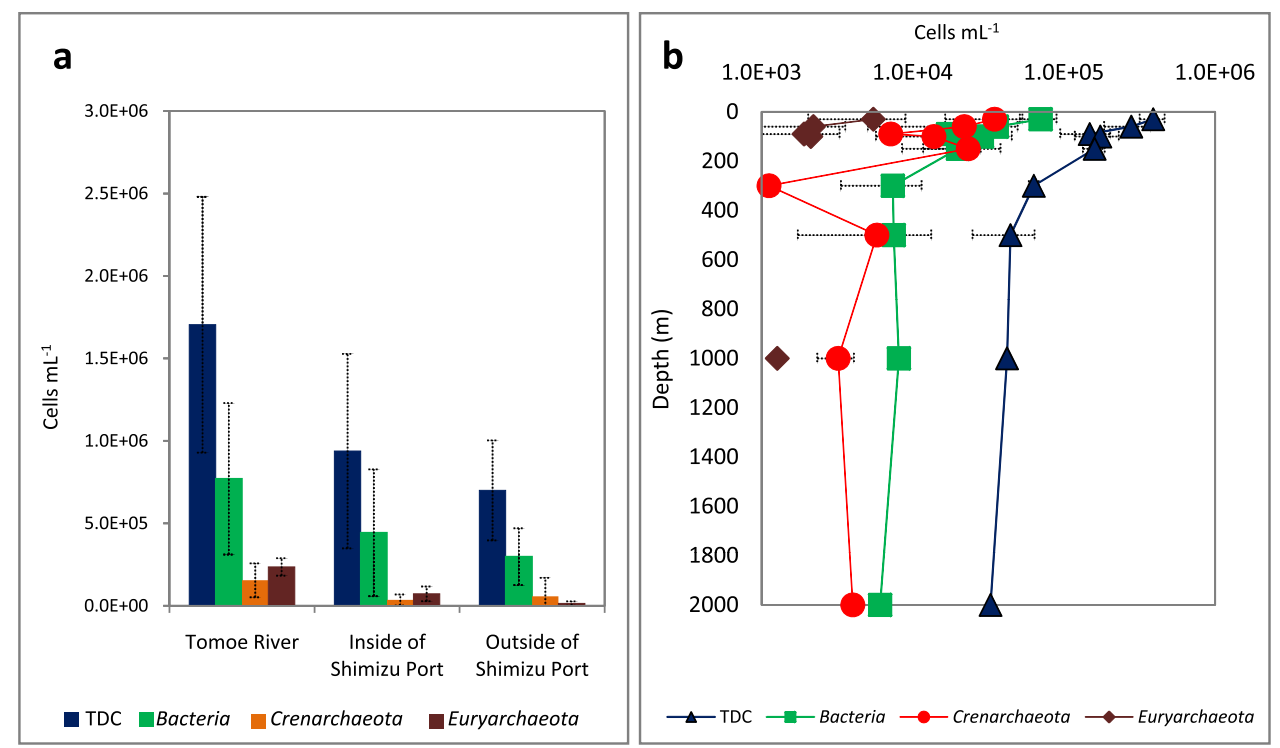

Fig. 3. Spatial distribution of TDC, Bacteria, Crenarchaeota, and Euryarchaeota from the mouth of the Tomoe River to Suruga Bay. a, Horizontal distribution from the surface to a depth of $20 \mathrm{~m}$; b, vertical distribution from a depth of $30 \mathrm{~m}$ to $2,000 \mathrm{~m}$. 


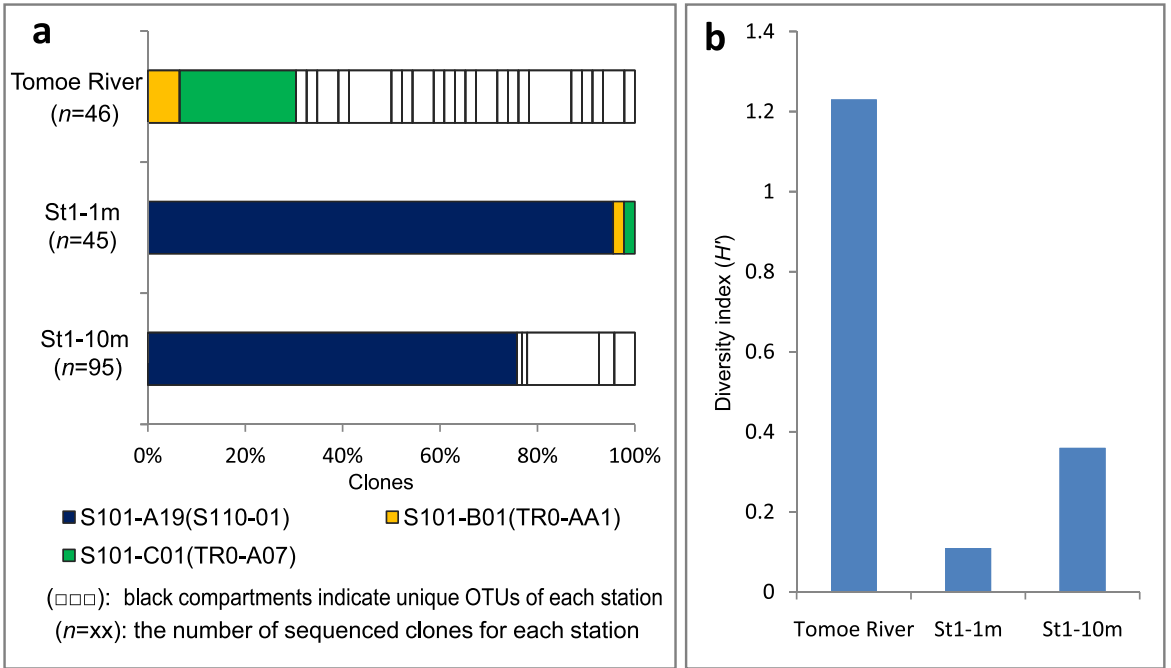

Fig. 4. Comparisons of the phylotypic archaeal communities. a, Phylogenetic relationships among archaeal communities; b, Diversity indices among archaeal communities. $(n=\mathrm{xx})$, numbers of sequenced clones.

Euryarchaeota in Shimizu Port are ascribable to the inflowing waters of the Tomoe River. Statistical analysis showed that the abundance of Euryarchaeota correlated significantly with the concentration of $\mathrm{NH}_{4}{ }^{+}(P<0.001$; Fig. $\mathrm{S} 3 \mathrm{~g}$ ), although this must be confirmed with further experiments. Crenarchaeota abundance showed no significant relationship to salinity, and Crenarchaeota abundance outside the port even tended to be higher than that inside the port (Fig. 3a).

The number of prokaryotes decreased vertically in parallel with TDC, Bacteria, Crenarchaeota, and Euryarchaeota. The proportion contributed by Crenarchaeota to TDC tended to increase with increasing depth, whereas that of Euryarchaeota tended to be low at depth (Fig. 3b). Planktonic Crenarchaeota comprised about $11 \%$ of TDC between depths of $100 \mathrm{~m}$ and 2,000 m, whereas Euryarchaeota comprised less than $2.3 \%$ of TDC. A similar trend has been reported in the offshore waters of California, in the North Pacific Ocean Gyre (8).

\section{Diversity, distribution, and functional characteristics of the archaeal community}

The diversity of the archaeal community represented by the OTUs was highest $\left(H^{\prime}=1.23\right)$ in the Tomoe River Mouth, and was more than three times higher here than at St $1-1 \mathrm{~m}$ or St1-10m (Fig. 4b). The OTUs found in the mouth of Tomoe River represented almost all the OTU groups collected at the other stations, except MGII. Many of the archaeal OTUs were unidentified at the point where the river water mass meets the bulk of the marine water. The lowest diversity was observed at St1-1m $\left(H^{\prime}=0.11\right)$, where the archaeal community simply consisted of three OTUs; two of them (S101$\mathrm{C} 01$ and S101-B01) were classified into the same cluster as OTUs TR0-A07 and TR0-AA1 from the Tomoe River, with similarities of $98 \%$ and $100 \%$, respectively, and the remaining dominant OTU S101-A19 was identical to the dominant OTU S110-01 of St1-10m, with 100\% homology. Moreover, TR0-A07 was closely related to both S101-A19 and S11001 , with similarities of $97 \%$. These findings suggest that a significant proportion of the marine planktonic archaeal community in Shimizu Port was derived from freshwater, from where they first invaded the coastal waters and then dispersed into pelagic waters.

When the newly collected OTUs were compared with known phylotypes of the world's oceans (Fig. 2), the dominant OTUs of St.1 (S101-A19 and S110-01), belonging to MGI, were found to be classified into the same cluster (cluster I) as representatives from various seas, such as the North Atlantic Ocean (AF223111), the coast of North American (M88075), the Cantabrian Sea (AF223114), the Santa Barbara Channel (U78195), Drake Passage North (AF223122), Drake Passage South (AF223125), and Arthur Harbor (AF223128). The second most-dominant OTU, S110-02 (14.7\%), belonging to Euryarchaeota MGII, was classified into the same cluster (cluster III) as a representative from the North Atlantic Ocean (AF223132). At the mixing front between the freshwater and marine water, St.1 contained dominant OTUs that occur as cosmopolitan archaeal phylotypes in the world's oceans.

Although the abundances of the Crenarchaeota and Euryarchaeota amounted to a significant proportion (11.6\%) of all the planktonic prokaryotes in the coastal zone of Suruga Bay, direct assessment of their contribution to the biogeochemical cycles at the mixing front of the river and marine waters remains problematic. Stable isotope and radiocarbon analyses of their specific membrane lipids (15), and microautoradiographic experiments $(13,33)$ showed that the Archaea are chemolithotrophic or mixotrophic, and can use dissolved inorganic carbon and organic substrates for growth and development. The archaeal gene for putative ammonia monooxygenase A (amoA) may oxidize ammonia to nitrite $(9,36,39)$, and archaeal amo $A$ copy numbers have also been shown to correlate with $\mathrm{NO}_{2}$ concentrations in mesopelagic waters of the eastern Mediterranean Sea (6). Könneke et al. (19) also successfully isolated a marine Crenarchaeota, Nitrosopumilus maritimus SCM1, which was identified as a chemolithotrophic archaeon that can fix carbon and aerobically oxidize ammonia to nitrite. These findings indicate 
that Crenarchaeota and Euryarchaeota contribute considerably to the carbon and nitrogen cycles in the coastal zone of Suruga Bay.

\section{Acknowledgements}

This study was partly supported by the Foundation for Riverfront Improvement and Restoration, Japan (2009). We acknowledge financial support by the Graduate School of Science and Technology, Shizuoka University; Special Research Fund for Future Program of Shizuoka University, Japan; and Vietnam International Education Development, Ministry of Education and Training, Vietnam. We thank Prof. Yoshimi Suzuki for his kind offer to use the autoanalyzer and encouragement throughout the study.

\section{References}

1. Amann, R.I., B.J. Binder, R.J. Olson, S.W. Chisholm, R. Devereux, and D.A. Stahl. 1990. Combination of 16S rRNA-targeted oligonucleotide probes with flow cytometry for analyzing mixed microbial populations. Appl. Environ. Microbiol. 56:1919-1925.

2. Borneman, J., and E.W. Triplett. 1997. Molecular microbial diversity in soils from Eastern Amazonia: Evidence for unusual microorganisms and microbial population shifts associated with deforestation. Appl. Environ. Microbiol. 63:2647-2653.

3. Brochier-Armanet, C., B. Boussau, S. Gribaldo, and P. Forterre. 2008. Mesophilic crenarchaeota: Proposal for a third archaeal phylum, the Thaumarchaeota. Nat. Rev. Microbiol. 6:245-252.

4. Buckley, D.H., J.R. Graber, and T.M. Schmidt. 1998. Phylogenetic analysis of nonthermophilic members of the kingdom Crenarchaeota and their diversity and abundance in soils. Appl. Environ. Microbiol. 64:4333-4339.

5. Church, M.J., E.F. DeLong, H.W. Ducklow, M.B. Karner, C.M. Preston, and D.M. Karl. 2003. Abundance and distribution of planktonic Archaea and Bacteria in the waters west of the Antarctic Peninsula. Limnol. Oceanogr. 48:1893-1902.

6. De Corte, D., T. Yokokawa, M.M. Varela, H. Agogué, and G.J. Herndl. 2009. Spatial distribution of Bacteria and Archaea and amoA gene copy numbers throughout the water column of the Eastern Mediterranean Sea. ISME J. 3:147-158.

7. DeLong, E.F. 1992. Archaea in coastal marine environments. Proc. Natl. Acad. Sci. USA 89:5685-5689.

8. DeLong, E.F. 2003. Oceans of Archaea. ASM News 69:503-511.

9. Francis, C.A., K.J. Roberts, J.M. Beman, A.E. Santoro, and B.B. Oakley. 2005. Ubiquity and diversity of ammonia-oxidizing archaea in water columns and sediments of the ocean. Proc. Natl. Acad. Sci. USA 102:14683-14688

10. Fuhrman, J.A., K. McCallum, and A.A. Davis. 1992. Novel major archaebacterial group from marine plankton. Nature 356:148-149.

11. Fukue, M., Y. Sato, H. Fujikawa, T. Kanegae, T. Inoue, and C.N. Mulligan. 2006. Role of Orido Bay and Shimizu Port in reducing the load of contaminants into Suruga Bay. J. Sch. Mar. Sci. Tech., Tokai Univ. 4:1-15.

12. Herfort, L., S. Schouten, B. Abbas, M.J.W. Veldhuis, M.J.L. Coolen, C. Wuchter, J.P. Boon, G.J. Herndl, and J.S. Sinninghe Damsté. 2007. Variations in spatial and temporal distribution of Archaea in the North Sea in relation to environmental variables. FEMS Microbiol. Ecol. 62:242-257.

13. Herndl, G.J., T. Reinthaler, E. Teira, H. van Aken, C. Veth, A. Pernthaler, and J. Pernthaler. 2005. Contribution of Archaea to total prokaryotic production in the deep Atlantic Ocean. Appl. Environ. Microbiol. 71:2303-2309.

14. Hershberger, K.L., S.M. Barns, A-L. Reysenbach, S.C. Dawson, and N.R. Pace. 1996. Wide diversity of Crenarchaeota. Nature 384:420.

15. Hoefs, M.J.L., S. Schouten, J.W. de Leeuw, L.L. King, S.G. Wakeham, and J.S. Sinninghe Damsté. 1997. Ether lipids of planktonic Archaea in the marine water column. Appl. Environ. Microbiol. 63:3090-3095.

16. Jurgens, G., K. Lindström, and A. Saano. 1997. Novel group within the kingdom Crenarchaeota from boreal forest soil. Appl. Environ. Microbiol. 63:803-805.

17. Karner, M.B., E.F. DeLong, and D.M. Karl. 2001. Archaeal dominance in the mesopelagic zone of the Pacific Ocean. Nature 409:507-510.
18. Kirchman, D.L., A.I. Dittel, R.R. Malmstrom, and M.T. Cottrell. 2005. Biogeography of major bacterial groups in the Delaware Estuary. Limnol. Oceanogr. 50:1697-1706.

19. Könneke, M., A.E. Bernhard, J.R. de la Torre, C.B. Walker, J.B. Waterbury, and D.A. Stahl. 2005. Isolation of an autotrophic ammonia-oxidizing marine archaeon. Nature 437:543-546.

20. MacGregor, B.J., D.P. Moser, E.W. Alm, K.H. Nealson, and D.A. Stahl. 1997. Crenarchaeota in Lake Michigan sediment. Appl. Environ. Microbiol. 63:1178-1181.

21. Massana, R., A.E. Murray, C.M. Preston, and E.F. DeLong. 1997. Vertical distribution and phylogenetic characterization of marine planktonic Archaea in the Santa Barbara Channel. Appl. Environ. Microbiol. 63:50-56.

22. Massana, R., E.F. DeLong, and C. Pedrós-Alió. 2000. A few cosmopolitan phylotypes dominate planktonic archaeal assemblages in widely different oceanic provinces. Appl. Environ. Microbiol. 66:1777-1787.

23. Murray, A.E., C.M. Preston, R. Massana, L.T. Taylor, A. Blakis. K. Wu, and E.F. DeLong. 1998. Seasonal and spatial variability of bacterial and archaeal assemblages in the coastal waters near Anvers Island, Antarctica. Appl. Environ. Microbiol. 64:2585-2595.

24. Porter, K.G., and Y.S. Feig. 1980. The use of DAPI for identifying and counting aquatic microflora. Limnol. Oceanogr. 25:934-948.

25. Saitou, N., and M. Nei. 1987. The neighbor-joining method: A new method for reconstructing phylogenetic trees. Mol. Biol. Evol. 4:406425.

26. Schleper, C., R.V. Swanson, E.J. Mathur, and E.F. DeLong. 1997. Characterization of a DNA polymerase from the uncultivated psychrophilic archaeon Cenarchaeum symbiosum. J. Bacteriol. 179:7803-7811.

27. Schloss, P.D., and J. Handelsman. 2005. Introducing DOTUR, a computer program for defining operational taxonomic units and estimating species richness. Appl. Environ. Microbiol. 71:15011506.

28. Somerville, C.C., I.T. Knight, W.L. Straube, and R.R. Colwell. 1989. Simple, rapid method for direct isolation of nucleic acids from aquatic environments. Appl. Environ. Microbiol. 55:548-554.

29. Stahl, D.A., and R. Amann. 1991. Development and application of nucleic acid probes, p. 205-248. In E. Stackebrandt, and M. Goodfellow (ed.), Nucleic Acid Techniques in Bacterial Systematics. John Wiley \& Sons, Chichester.

30. Stoica, E., and G.J. Herndl. 2007. Contribution of Crenarchaeota and Euryarchaeota to the prokaryotic plankton in the coastal northwestern Black Sea. J. Plankt. Res. 29:699-706.

31. Takenaka, T., T. Tashiro, A. Ozaki, H. Takakubo, Y. Yamamoto, T. Maruyama, K. Nagaosa, H. Kimura, and K. Kato. 2007. Planktonic bacterial population dynamics with environmental changes in coastal areas of Suruga Bay. Microbes Environ. 22:257-267.

32. Teira, E., T. Reinthaler, A. Pernthaler, J. Pernthaler, and G.J. Herndl. 2004. Combining catalyzed reporter deposition-fluorescence in situ hybridization and microautoradiography to detect substrate utilization by Bacteria and Archaea in the deep Ocean. Appl. Environ. Microbiol. 70:4411-4414.

33. Teira, E., P. Lebaron, H. van Aken, and G.J. Herndl. 2006. Distribution and activity of Bacteria and Archaea in the deep water masses of the North Atlantic. Limnol. Oceangr. 51:2131-2144.

34. Thompson, J.D., D.G. Higgins, and T.J. Gibson. 1994. CLUSTAL W: Improving the sensitivity of progressive multiple sequence alignment through sequence weighting, position-specific gap penalties and weight matrix choice. Nucleic Acids Res. 22:4673-4680.

35. Ueda, T., Y. Suga, and T. Matsuguchi. 1995. Molecular phylogenetic analysis of a soil microbial community in a soybean field. Eur. J. Soil Sci. 46:415-421.

36. Venter, J.C., K. Remington, J.F. Heidelberg et al. 2004. Environmental genome shotgun sequencing of the Sargasso Sea. Science 304:66-74.

37. Wang, Q., G.M. Garrity, J.M. Tiedje, and J.R. Cole. 2007. Naïve Bayesian classifier for rapid assignment of rRNA sequences into the new bacterial taxonomy. Appl. Environ. Microbiol. 73:5261-5267.

38. Wells, L.E., M. Cordray, S. Bowerman, L.A. Miller, W.F. Vincent, and J.W. Deming. 2006. Archaea in particle-rich waters of the Beaufort Shelf and Franklin Bay, Canadian Arctic: Clues to an allochthonous origin? Limnol. Oceanogr. 51:47-59.

39. Wuchter, C., B. Abbas, M.J.L. Coolen et al. 2006. Archaeal nitrification in the ocean. Proc. Natl. Acad. Sci. USA 103:12317-12322. 